\title{
Palabras en homenaje al Dr. Joaquín Roberto Bárcena (San Pedro de Atacama, 24 de marzo de 2015)
}

Tengo el honor de introducir algunas palabras para el merecido homenaje que la Comisión Organizadora del Taller Qhapaq Ñan I ha decidido otorgar en mérito a la trayectoria y en reconocimiento por sus aportes a la arqueología inka al Dr. Joaquín Roberto Bárcena.

Esta ceremonia reconoce en forma simbólica, pero con la más alta investidura, la labor de este arqueólogo radicado en Mendoza, que en las últimas décadas recibió el reconocimiento explícito del sistema científico de nuestro país y de países vecinos por la labor investigativa de toda una vida que, afortunadamente, ha podido cumplir con los postulados que sostienen el quehacer científico: la investigación con intachable ética profesional y la formación de recursos humanos. Asimismo, el Dr. Bárcena ha servido de espejo, sostén y progreso para varios discípulos, alumnos y colegas que lo han imitado, con lo cual ha venido ya siendo tributado, si tomamos la frase de Concepción Arenal: "El mejor homenaje que puede tributarse a una buena persona es imitarla".

Antes de comenzar a detallar solo algunos aspectos de la prolífica actividad del Dr. Roberto Bárcena, quiero destacar que cuando en primera instancia Ángel Alberto Manzo le sugirió la posibilidad de un homenaje y cuando posteriormente yo hice lo propio, comunicándole la decisión tomada por los colegas y referentes chilenos, expresó que lo agradecía infinitamente, pero que -por supuesto, como era esperable en él- no se sentía merecedor de tamaña distinción por considerar que sus productos científicos habían sido intensos, por cierto, pero no más de los que también han realizado varios de los colegas que están aquí presentes. Aún así, haciendo uso de su aplomado criterio y tratando de "ponerlo en su justo lugar", como él mismo diría, me comunicó la orgullosa aceptación a la distinción a la que hoy estamos asistiendo.

Comentábamos y esperábamos junto a colegas argentinos y, fundamentalmente con Carlos González, que Bárcena no tomara el homenaje como un reconocimiento que le era conferido por haber llegado al final de su trayectoria como investigador, o que el mismo le significara una despedida de la actividad. Por el contrario, esta distinción debe ser un reconocimiento al mérito de sus prolíficas acciones y una distinción por haber desarrollado una labor profesional comprometida en todo sentido con el quehacer de la ciencia arqueológica, que aún tiene enorme potencial para el futuro. Lo mejor seguramente está por venir.

Debido a los aconteceres personales y en relación con la salud del Dr. Bárcena, damos por descontada su pronta sanación, ya que conocemos algo de la inquebrantable fortaleza física. Para ilustrarla, solo basta contar un dato a manera de anécdota que quizás no todos conozcan: Roberto no solo usa medios convencionales de transporte, sino que elige también los más extremos. Desde hace años y hasta la actualidad, recorre con su cuatriciclo todos y cada uno de los rincones de la cordillera muestreados en las áreas de sus proyectos, y en una de sus últimas 
campañas, llegó a Mendoza algo dolorido en una de sus extremidades, sin haberse dado cuenta de que tenía ni más ni menos que una fractura que le había propinado el áspero y farragoso terreno que había prospectado; quizás ello resuma nuestro optimismo por su rápida recuperación.

Saliendo de esta informalidad, yo creo que para Roberto será doblemente gratificante recibir esta distinción en un marco como el del Taller Qhapaq Ñan I, donde están representadas todas las voces de quienes se han acercado a este costal tan relevante de la arqueología andina, como son los estudios inkaicos.

En lo que a mí concierne, cuando el Comité Organizador me delegó esta tarea comencé a pensar cómo abordarla, porque significaba en lo personal una doble responsabilidad: la de dejar de lado las subjetividades propias de la amistad y compañerismo que me unen a Roberto, para así juzgar lo que realmente se debe juzgar; y por otra, elegir correctamente si era conveniente valorar las actividades de la vida profesional repasando sus encomiables actividades o exponer lo que significa Bárcena como persona en los diversos contextos en los que ha actuado o se ha desempeñado.

Siguiendo lo que Roberto creo que querrá -y espero no equivocarme en ello- es que he optado por la primera, apoyándome en sus trabajos como investigador, como gestor científico, como docente o como arqueólogo; dimensiones que, en definitiva, siempre primaron en el espíritu de este homenaje. No obstante, inyectaré por supuesto algunos rasgos de su conducta que son realmente difíciles de separar de su actividad profesional.

En primer término, permítanme excusarme por sintetizar las actividades científicas y de docente investigador universitario del Dr. Bárcena, pero las mismas son demasiado extensas (casi 100 páginas); resumir su actuación profesional nos llevaría realmente más tiempo del que tenemos, de manera que con su anvencia enumeraré solo las que a mi criterio han sido las más relevantes de su vasta trayectoria.

Roberto Joaquín Bárcena nació en Lomas de Zamora (Buenos Aires) un 12 de octubre de 1944, pero a temprana edad se trasladó junto a su familia a la Provincia de Mendoza y allí desarrolló sus actividades iniciales de escolaridad. En la etapa secundaria de su formación, obtuvo los títulos de Operador Radiotelegrafista (Escuela Nacional de Educación Técnica Ing. Pablo Nogués, Consejo Nacional de Educación Técnica), en 1962, y de Bachiller y Agricultor Enólogo (Liceo Agrícola y Enológico D. F. Sarmiento, Universidad Nacional de Cuyo), en 1963.

Sus primeros pasos universitarios los da en la Facultad de Filosofía y Letras de la Universidad Nacional de Cuyo, obteniendo los grados de Profesor y Licenciado en Historia en el año 1974, ambos con el mejor promedio de la promoción. Posteriormente, en el año 1998, obtiene el grado de Doctor en Geografía e Historia, especialidad Prehistoria (Apto cum laude, por unanimidad del jurado) en la Facultad de Geografía e Historia, Universidad Nacional de Educación a Distancia de Madrid, España. Su tesis -como no podía ser de otra manera- se tituló: "La dominación 


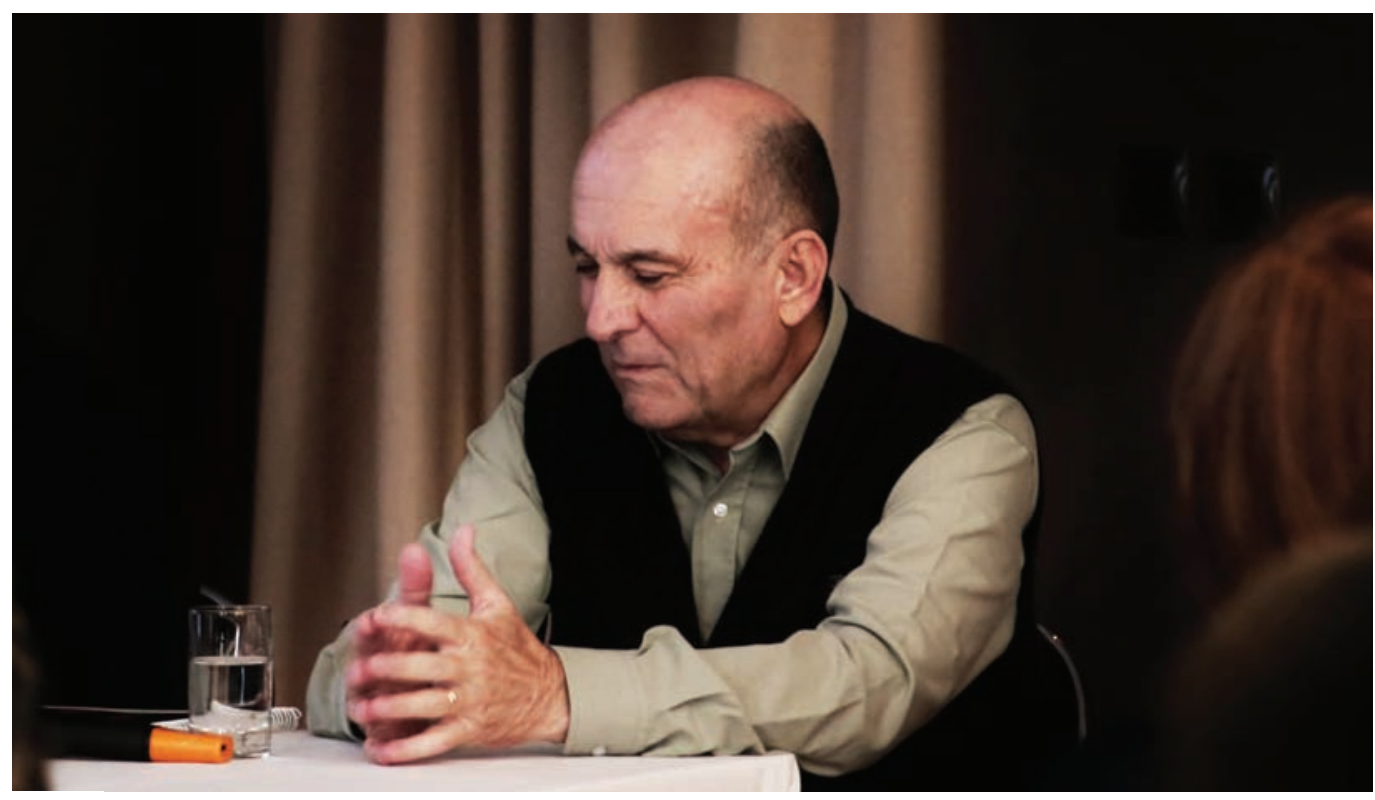

Dr. Joaquín Roberto Bárcena.

incaica en el extremo austral oriental del Tawantinsuyu: estrategias del dominio inka en Cuyo", bajo la dirección del reconocido investigador paleolitista Dr. Eduardo Ripoll Perelló.

Desde el año 1999, ocupa el cargo de Investigador Principal del Consejo Nacional de Investigaciones Científicas y Tecnológicas (CONICET) y ha sido además Director del Instituto de Ciencias Humanas, Sociales y Ambientales (INCIHUSA) del CONICET en Mendoza, posición que desde el año 2005 ha obtenido por concursos nacionales abiertos, con dictámenes unánimes del jurado. Sin embargo, debemos resaltar que su cargo de mayor gravitación para el sistema científico nacional lo ejecutó hasta hace muy poco tiempo, cuando fuera designado como Director del Centro Científico Tecnológico CONICET-Mendoza, por unanimidad por el Consejo Directivo del citado centro para el período 2010-2012 y luego durante el ciclo 2012-2014, desarrollando una prolífica performance, que en este caso benefició a las diversas disciplinas científicas que desarrolla el cct de esta provincia cuyana.

Entre otras actividades, el Dr. Bárcena se ha desarrollado además como Jefe del Grupo de Antropología, INCIHUSA-CONICET (2005-2015), Asesor Honorario de la Comisión Nacional de Museos y de Monumentos y Lugares Históricos, Asesor Científico Honorario del Programa Qhapaq Nan Camino Principal Andino en la Ex Secretaría de Cultura de la Nación (devenido hoy en Ministerio de Cultura de la Nación), Coordinador Científico del Programa Qhapaq Ñan Camino Principal Andino de la Secretaría de Cultura de la Provincia de Mendoza, Miembro correspondiente de la Academia Nacional de la Historia, Miembro de Número de la Junta de Estudios Históricos de Mendoza, Miembro correspondiente de la Reial Acadèmia de Bones Lletres (Barcelona, España), por solo citar algunos de los más relevantes. 
Su profusa actividad docente le valió alcanzar la jerarquía de Profesor Titular Efectivo de Arqueología Prehistórica en la Facultad de Filosofía y Letras de la Universidad Nacional de Cuyo, en Mendoza, casa de altos estudios en la que también está dejando su impronta como Director del Instituto de Arqueología y Etnología desde el año 2011 hasta la actualidad. Ha sido asimismo consultor de distintas universidades nacionales e internacionales y alcanzó el grado honorario de Profesor Extraordinario, en la categoría de Profesor Visitante, de la Universidad Nacional de La Rioja.

Igualmente, ha obtenido numerosas becas de investigación en el país y en el extranjero, entre las que destacan:

- Subsidio del Programa Nacional para la movilidad de profesores de universidad e investigadores españoles y extranjeros. Concedido en concurso internacional abierto por la Secretaría de Estado de Universidades e Investigación (Dirección General de Universidades) del Ministerio de Educación y Ciencia de España (abril de 2005).

- Beca (desplazamiento y alojamiento) de la Universidad Internacional de Andalucía, Sede Iberoamericana Santa María de La Rábida, para realizar la ॥ Maestría en Conservación del Patrimonio. La Rábida (febrero de 2003).

- Becario ad honorem del Instituto de Cooperación Iberoamericana (1985).

- Becario de la Universidad Internacional Menéndez Pelayo para realizar el Seminario de posgrado sobre "Las Crónicas de Indias". Sevilla (1984).

- Becario de la misma universidad para realizar el Seminario de posgrado "Metodología de la investigación en arte parietal prehistórico". Palacio de la Magdalena, Santander (junio de 1984).

También ha sido merecedor de numerosas becas nacionales e internacionales otorgadas por el Concejo Nacional de Investigaciones Científicas y Tecnológicas.

En lo relativo a las actividades editoriales, ha ejercido la Dirección y Edición de Xama (Unidad de Antropología, INCIHUSA, CRICYT), publicación categoría 1 (Latindex); y también de Anales de Arqueología y Etnología (IAE, Facultad de Filosofia y Letras de la UNCuyo) (1997-2000) (20112015), incorporada al Núcleo de Publicaciones Científicas, CAICYT-CONICET.

Ha sido presidente de los dos últimos Congresos Nacionales de Arqueología Argentina en Mendoza, en el mes de octubre del año 2010 y en La Rioja durante el mes de abril del año 2013. La profesión le ha permitido colaborar además en actividades altamente sensibles relacionadas con la defensa de los Derechos Humanos, al ser convocado por el Juzgado de Garantías № 5 del Poder Judicial de la Provincia de Mendoza, para la búsqueda de personas desaparecidas durante la última dictadura militar, utilizando metodologías arqueológicas en relación con las aplicaciones de la Antropología Forense. Asimismo ha incursionado en el campo de la arqueología contractual, en el que desarrolló algunas experiencias sobre la evaluación de impacto sobre bienes culturales, medidas de mitigación y/o rescate arqueológico en áreas limítrofes entre las Provincias de San Juan y Mendoza. 
Ha sido galardonado con los siguientes premios y distinciones:

- Premio Cumbres de América (Cultura). Municipalidad de Las Heras (Mendoza, 20 de sept. de 2001).

- Mención especial libro mejor impreso y editado en la Argentina bienio 1998-1999; categoría obras de estudio y consulta, por Arqueología de Mendoza: las dataciones absolutas y sus alcance. Cámara Argentina de Publicaciones (Buenos Aires, 17 de mayo de 2000).

- Premio Academia Nacional de la Historia. Medalla de oro al egresado con mayor promedio en Historia Argentina y Americana de la Carrera de Historia de la Universidad Nacional de Cuyo (y mejor egresado de la promoción. Buenos Aires, 1974).

Fue también distinguido e incorporado por sus relevantes actividades como:

- Académico correspondiente en la provincia de Mendoza de la Academia Nacional de la Historia (Buenos Aires, 11 de noviembre de 1997). Disertación de incorporación: "Arqueología, historia y patrimonio cultural" (Buenos Aires, 14 de agosto de 2001).

- Académico correspondiente en Mendoza de la Reial Acadèmia de Bones Lletres de Barcelona, España (Barcelona, 14 de enero de 1999).

- Académico de número de la Junta de Estudios Históricos de Mendoza (Mendoza, 4 de diciembre de 1998). Disertación de incorporación: Arqueología e Historia: la indagación científica en los límites del registro arqueológico y de la documentación histórica (Mendoza, 24 de septiembre de 1999).

Asimismo, fue consultado, por su experticia profesional, por diversos organismos vinculados a la Defensa y Protección del Patrimonio Arqueológico de las Provincias del Nuevo Cuyo, Parques Nacionales y Parques Provinciales, como las acciones desarrolladas en el Parque Provincial Aconcagua del Noroeste de Mendoza, por solo citar uno entre tantos casos.

Dentro de la producción científica, posee más de 100 artículos (entre libros, publicaciones científicas y de divulgación masiva) en diversos órganos de publicación nacional e internacional, que comprenden todas las etapas de la prehistoria regional del área cuyana, abarcando los estudios de las primeras ocupaciones humanas, la época de dominación inka, las primeras fundaciones hispánicas o la arqueología de templos eclesiásticos de épocas republicanas. En este ítem, su último capítulo de libro en prensa y próximo a ser editado es: "Qhapaq Ñan: Andean road system through the Collasuyu to the end of the Tawantinsuyu", en The great Inka road engineering an Empire, R. Matos, Comp.; S. Barrows, ed. Washington: National Museum of the American Indian, Smithsonian.

Quiero destacar que a partir de la década de los noventa comenzó a publicar obras de singular relevancia, como la edición de Arqueología de Mendoza: las dataciones absolutas y sus alcan$c e$, un libro que, en mi opinión, es altamente recomendable para cualquier profesional de la 
arqueología. En tal obra, Bárcena plasma con claridad sus actividades arqueológicas en diversos momentos de la prehistoria cuyana, contrastando el registro arqueológico con experimentación de los fechados radiocarbónicos y por termoluminiscencia por él efectuados. El resultado devino en un excelente tratado referencial sobre los alcances y limitaciones teóricas, metodológicas y técnicas de las mediciones isotópicas con fines cronológicos aplicados en arqueología.

Entre sus contribuciones a la dominación inkaica en la Argentina, rescatamos el tratamiento de una perspectiva ampliamente comprensiva desde lo espacial, que comprende las tierras altas y bajas del Centro-oeste Argentino (COA) y también la porción más meridional del Noroeste Argentino (NOA), en los que prospectó y excavó sitios imperiales y de las poblaciones locales relacionados con estos últimos.

Sus estudios analíticos sobre materiales en registros artefactuales de altura y sobre la funcionalidad de los tambos en la provincia de Mendoza, así como el registro y excavación de sitios en la cordillera riojana solo han sido superados por el redescubrimiento y por sus importantes aportes acerca del notable sitio Paso del Lamar, ámbito donde el Inka exteriorizó su poder a través de una arquitectura que comprende elementos semejantes a los sitios más conspicuos ubicados en el Kollasuyu.

Sobre la organización de eventos acerca de la problemática inka, Bárcena fue uno de los miembros fundadores del Simposio Tawantinsuyu, que a partir del Congreso Nacional de Arqueología Argentina realizado en Córdoba en el año 1999, se convirtió en un verdadero "clásico", con numerosas participaciones de colegas tanto del medio nacional, como de países vecinos y de alejadas latitudes. Con ahínco y un encomiable espíritu ordenativo, participa de las coordinaciones y organización del citado evento en los congresos nacionales argentinos. En varias ocasiones y aun hasta estos días, le ha cabido a nuestro homenajeado la no menos compleja tarea de edición y publicación de los resultados de las reuniones, siempre lográndolo de manera exitosa.

Para resumir, podemos decir que se le otorga la distinción a un excelente arqueólogo, de permanente actualización, de incansable actividad, un gran estratega y planificador, muy sistemático y organizado. Un individuo firme en sus proyectos y de sólidas convicciones, con grandes cualidades de liderazgo, seguro de sus acciones $y$, por sobre todas las cosas, una persona que se ha distinguido por la ética, la alta responsabilidad en cada una de sus intervenciones y por su palabra. Siempre ha mirado frontalmente a la vida. Nunca ha aguantado desplantes, agravios, calumnias u ofensas para él o para su equipo de investigación, a cuyos miembros además siempre les ha permitido ascender en la medida en que realicen los méritos pertinentes.

Sergio Martin *

* Instituto Nacional de Antropología y Pensamiento Latinoamericano. Profesor adjunto de Antropología Social y Cultural FCAd, Universidad Nacional de Entre Ríos. 